\title{
Prospects for cultivation Triticum aestivum L. and Secale cereale L. on the barren substrates
}

\author{
Lilia M. Safiullina*, Galia M. Mukhametova, Alfia I. Fazlutdinova and Natalia V. Sukhanova
}

Bashkir State Pedagogical University n. a. M. Akmulla, Ufa, 450008, Russia

\begin{abstract}
Studies on the influence of polymer hydrogels from different manufacturers on the morphometric parameters of microalgae cells of Chlorella vulgaris, Eustigmatos magnus and Scotiellopsis $s p$. and the possibility of their joint use in sowing seeds of Triticum aestivum and Secale cereale in barren substrates are presented. The optimal effects of a particular algae crop in combination with a particular hydrogel and their dependence on the soil type with a joint effect on the seeds of cereal crops were revealed. The germination ability analysis of higher plants seeds of two studied species showed the effectiveness of "BSPU" hydrogel with E. magnus culture liquid when sown on sand. Indicators of the length of sprouts and roots of cereals seeds allowed us to build a number of effective effects of microalgae: E. magnus > S. sp. > Ch. vulgaris. The results of the study revealed the individuality of the crop in combination: substrate/hydrogel/microalgae, which must be taken into account for the possibility of their effective joint use in reclamation processes.
\end{abstract}

\section{Introduction}

The intensification of agriculture poses challenges to agriculture related to the need to increase the potential and fertility of the soil. Such negative processes as soil depletion by biogenic composition, erosion, and destructuring remain one of the most urgent problems nowadays. The development and implementation of a set of measures to reduce the negative qualities of soils in agriculture contribute to the growth of agricultural productivity $[1,2]$.

Hydrophilic acrylic polymers (PAA) are widely used in various fields of the national economy as super absorbents. A promising area of their use is the production of moisture-holding preparations for the needs of agriculture [3]. The introduction of PAA-based preparations into the soil of arid regions has an evident positive effect on the growth and survival of plants [4]. In addition, polyacrylamide gel can be considered as a potential carrier for insecticides, fungicides, herbicides, and fertilizers [5]. Hydrophilic polymers can change soil characteristics due to their ability to adsorb a large amount of water, by 400 or more times exceeding its own weight [4].

At the same time, in addition to water, plants need "top dressing", in the form of fertilizers. Over the past few decades, work has been underway to improve the agrochemical properties of the soil. This is mainly achieved by mineral fertilization. Under their effect, it is possible to correct the lack of nutrients in the soil and increase its fertility. One type of organic fertilizer is microalgae biomass [6]. Their role is essential in such habitats where higher plants are either absent or underdeveloped. In particular, in areas subjected to strong man-made impacts (dumps of different origin and chemical composition, territories contaminated during oil production and processing, etc.).

Under these conditions, algae are the only source of organic matter, or they account for most of the synthesized primary products of the ecosystem, and the death of algocenosis can lead to the entire biocoenosis destruction. With a high reproduction rate, soil algae are an important mechanism of elastic resistance of terrestrial biocenoses to destabilizing factors, including anthropogenic origin [7]. It has been experimentally proved that the biomass of soil algae can improve the physical and chemical regime of soils [8].

Algae biomass enriches the soil with nitrogen, phosphorus, potassium, iodine and a significant amount of trace elements. At the same time, microalgae decompose faster in the soil than manure fertilizers, do not clog it with weed seeds, larvae of harmful insects and spores of phytopathogenic fungi; they help to increase soil fertility, recultivation, replenishment of organic matter reserves and increase crop productivity [9; 10]. In addition, experimental studies [11] have shown the possibility of using hydrogels to improve the water-holding capacity of soils in conjunction with microalgae, as a result of which the effect of growth stimulation was observed.

In this regard, the possibility of joint use of polymer hydrogel and culture liquid of microalgae is considered as a promising solution to problems in arid regions agriculture and regions with disturbed soil cover.

The aim of the work was to study the effect of hydrogels from different manufacturers on microalgae

\footnotetext{
* Corresponding author: saflilya@mail.ru
} 
cells and the germination of Triticum aestivum and Secale cereale seeds on the barren substrates.

The tasks were: to evaluate the influence of hydrogels from different manufacturers on the morphometric parameters of three microscopic algae strains; to analyze the combined effect of moistureswelling hydrogels and culture liquid of microalgae on the germination, growth and viability of $T$. aestivum and $S$. cereale seedlings in various types of soil.

\section{Material and methods}

The study was conducted in two stages. First of all, it was necessary to determine the effect of the selected hydrogels on microscopic algae. The control was a culture liquid of the studied type without adding hydrogel. For the experiment, the following hydrogels were taken: based on a copolymer of diallyldimethylammonium chloride and acrylamide, developed at the Department of Chemistry of the BSPU named after M. Akmulla (hereinafter "BSPU"); Aquasorb $3005 \mathrm{KL}$ (medium), manufacturer country -France (hereinafter "France"); Stockosorb 660 micro, manufacturer country -Germany (hereinafter "Germany"). The absorption capacity of "BSPU" hydrogel is 1 gram per - 1 liter of liquid, while "France" and "Germany" hydrogels have 1 gram -0.3 liters of liquid. The following microalgae strains were used as a test object: Chlorella vulgaris (76.532-06*): BCAC 76*. (Chlorella vulgaris var. viridis Chodat 1913). Chodat R. (Geneva strain 45). Cellularized from fresh water. Dep.: SAG (211-12); Eustigmatos magnus (Baikal): BCAC 234. Russia, Republic of Buryatia, Frolikhinsky State Reserve territory. Scotiellopsis sp. (Scotiellopsis rubescens P3): BCAC 302. The Republic of Bashkortostan. Surroundings of the Pavlovka village, spruce forest: deciduous fall. The microorganisms were cultured for two weeks, followed by counting the number of cells in the Goryaev counting chamber $(6.34$ $\times 10^{6} \mathrm{~cm}^{3}-$ Ch. vulgaris, $0.76 \times 10^{6} \mathrm{~cm}^{3}-$ E. magnus, $0.75 \times 10^{6} \mathrm{~cm}^{3}-S$. $s p$.). The optical density of the culture liquid was measured using a photoelectric colorimeter (KFK-3 - "3OM3"), which was carried out at both stages of the study (table 1).

Table 1. Optical density of microalgae

\begin{tabular}{|c|c|c|c|c|}
\hline № & $\begin{array}{c}\mathrm{H}_{2} \mathrm{O} \\
\text { dist. }\end{array}$ & Ch. vulgaris & E. magnus & S. sp. \\
\hline 1 & 0.000 & $0.256 \pm 0.28$ & $0.199 \pm 0.32$ & $0.197 \pm 0.26$ \\
\hline 2 & 0.000 & $0.252 \pm 0.30$ & $0.198 \pm 0.30$ & $0.193 \pm 0.32$ \\
\hline 3 & 0.000 & $0.251 \pm 0.27$ & $0.193 \pm 0.28$ & $0.193 \pm 0.37$ \\
\hline
\end{tabular}

$10 \mathrm{ml}$ of culture liquid was poured into test tubes with hydrogel. The examination was performed in two repetitions on $3 \mathrm{rd}, 7 \mathrm{th}, 14 \mathrm{th}, 21 \mathrm{st}$ and 28 th days, taking into account the percentage of live/dead cells, morphometric changes, cell color, and the effect on the process of autosporogenesis. During each examination, the diameter of 50 cells was measured.

The second stage was to evaluate the combined effect of hydrogels and culture fluids of microalgae on the germination and length of seedlings and rootlets of $T$. aestivum and $S$. cereale seeds. Seeding was carried out on barren substrates according to the principle of aggregation toponymics [12], where clay, sand and finestone expanded clay were taken as the soil $[13,14]$.

Before the experiment, the substrates were preprepared: the clay was dried, then the clay and the expanded clay were grained with a mortar and afterwards all three types of substrate were sifted. Plants were grown in test tubes [15]. T. aestivum ("Ekada 70" grade) and $S$. cereale ("Saratovskaya 1" grade) were used for the research. Seeds, in the amount of 50 pieces in each setting up of the experiment, were pre-soaked for a day in the culture liquid of the studied microalgae strains. Hydrogel was poured in test tubes with soil ("BSPU" in the amount of $0.01 \mathrm{~g}$, "France"," Germany" - $0.03 \mathrm{~g}$ ), seeds were laid and watered with culture liquid. The percentage of germination and sprouts and rootlets length of two plant species seeds were determined on the 10th day according to the standard method [16].

\section{Results and discussion}

In the control, up to 28th day from the start of viewing, morphological parameters of the cell strains $C h$. vulgaris, E. magnus and $S$. sp. corresponded to the description of the diagnosis of the species [17, 18]: the boundaries of the internal contents of the cell were well defined, the structures were clearly distinguishable, the color of the cells was -bright green, and the presence of autospores was observed. The influence of the "BSPU" hydrogel on Ch. vulgaris caused homogeneity of the internal contents on the third day, while they retained a bright green color, and there were sporadic autospores. For E. magnus, similar distortions were revealed in three experimental samples on the 7 th day. In addition, in the "France" sample, the color of the entire culture changed to pale yellow, and a high percentage of dead cells $(10.52 \%)$ was observed. In the remaining two samples, similar color and increased cell lysis of this strain were recorded on the $21 \mathrm{st}$ day. Moreover, the effect of "France" hydrogel caused plasmolysis of $90 \%$ of cells and on the 28th day, complete death of the culture.

Influence of "France" and "Germany" hydrogels did not cause changes in the morphological parameters of Ch. vulgaris until the 21 st day. However, on day 7 for $S$. $s p$. cells, the same hydrogels showed homogeneity and single plasmolysis of the internal contents, while the culture retained a bright green color. On day 21, the percentage of dead Ch. vulgaris cells in the "BSPU" and "Germany" samples was more than $10 \%$, and the cells also had homogeneous internal contents. On day 28, plasmolysis of $30 \%$ of cells was observed in the cells of two samples with hydrogel. In the "BSPU" sample, cells were eliminated. This hydrogel revealed a strong toxic effect on two algae strains, while $S$. $s p$. showed high resistance to it during the whole period of the experiment, without revealing any morphological deviations. During the experiment, there were no 
changes in the average minimum size parameters of microalgae (Fig. 1).

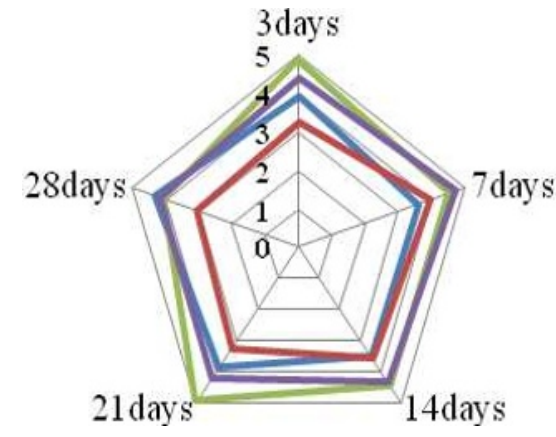

\section{Chlorella vulgaris}

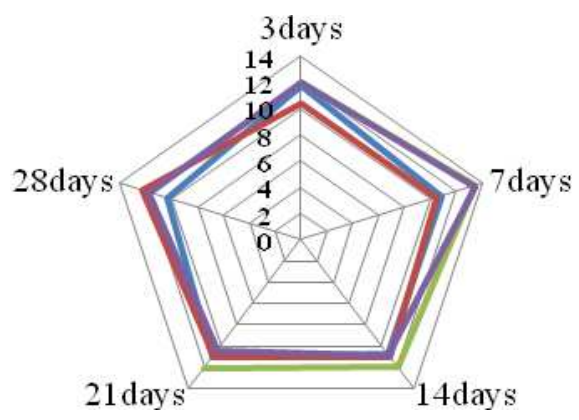

Eustigmatos magnus

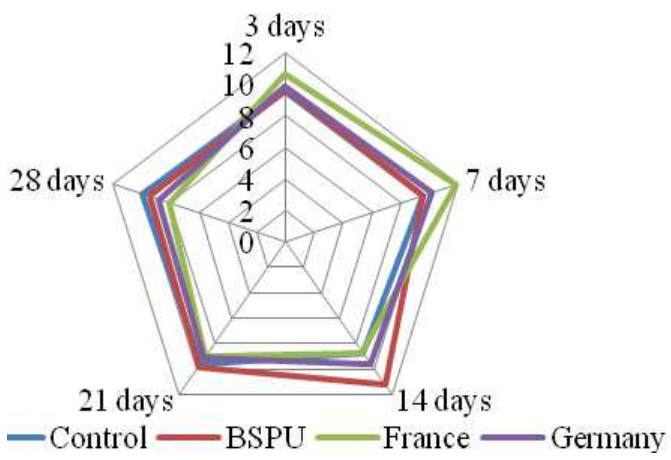

Scotiellopsis sp.

Fig. 1. Influence of moisture-swelling hydrogels on morphometric indicators of microalgae (average minimum cell size, microns)

At the same time, the cell diameter remained in the range specified in the determinants $[17 ; 18]$. Only in the "BSPU" samples, in comparison with the control, there was a tendency to the diameter reduction of the $C h$ Vulgaris cells - the minimum average cell size in this sample was 3.43 microns. The maximum value (up to 4.57 microns) was in the "France" sample. For the $E$. magnus strain, the average smallest cell diameter was observed in the "France" sample (9.91 microns), the maximum -"Germany" (11.67 microns). The average value of the minimum size of $S$. $s p$. cells was in the "Germany" sample - 9.52 microns, the maximum value was in the "BSPU" sample - 9.9 microns. In general, the inhibition of cell growth corresponded to a distortion of the morphological parameters of microalgae and revealed individuality concerning the toxic effect on the specifically studied strain.

For the next stage of the research, cultures $T$. aestivum ("Ekada 70" grade) and $S$. cereale ("Saratovskaya 1" grade) were used. Seeds, in the amount of 50 pieces in each setting up of the experiment, were pre-soaked for a day in the culture liquid of the studied microalgae strains. Hydrogel was poured in test tubes with soil ("BSPU" in the amount of $0.01 \mathrm{~g}$, "France"," Germany" - 0.03 g), seeds were laid and watered with culture liquid. The percentage of germination of two types of seeds was determined on the 10th day according to the standard method [16]. In general, the results of the experiment in all soil samples together with three types of hydrogel, in the control, showed low germination of $T$. aestivum and $S$. cereal seeds (table 2). In the sand, when using "BSPU" hydrogel in two species, it was only 10 and $20 \%$, respectively.

Table 2. Germination of seeds of Triticum aestivum / Secale cereale $(\%)$

\begin{tabular}{|c|c|c|c|}
\hline \multicolumn{4}{|c|}{ Control ( $\mathrm{H}_{2} \mathrm{O}$ dist. $)$} \\
\hline$\underbrace{\text { hydrogel }}_{\text {substrate }}$ & clay & sand & $\begin{array}{l}\text { expanded } \\
\text { clay }\end{array}$ \\
\hline BSPU & $34 / 20$ & $" 10 / 20$ & $26 / 15$ \\
\hline France & $28 / 26$ & $30 / 26$ & $30 / " 18$ \\
\hline Germany & $" 18 / 20$ & $" 16 / 20$ & $20 / " 10$ \\
\hline \multicolumn{4}{|c|}{ Chlorella vulgaris } \\
\hline BSPU & $40 / 55$ & $64 * / 75^{*}$ & $62 * / 50$ \\
\hline France & $62 * / 70 *$ & $36 / 48$ & $48 / 56$ \\
\hline Germany & "16/40 & $26 / 20$ & $44 / 60 *$ \\
\hline \multicolumn{4}{|c|}{ Eustigmatos magnus } \\
\hline BSPU & $40 / 70^{*}$ & $74 * / 74 *$ & $60 * / 50$ \\
\hline France & $26 / 42$ & $" 18 / 42$ & $42 / 40$ \\
\hline Germany & $48 / 40$ & $54 / 68^{*}$ & $20 / 34$ \\
\hline \multicolumn{4}{|c|}{ Scotiellopsis sp. } \\
\hline BSPU & $40 / 58$ & $64 * / 65 *$ & $48 / 60 *$ \\
\hline France & $" 18 / 36$ & $30 / 52$ & $34 / 50$ \\
\hline Germany & $20 / 26$ & $26 / 60 *$ & $34 / 70 *$ \\
\hline
\end{tabular}

However, under the same conditions, with culture fluids adding Ch. vulgaris, E. magnus and $S$. $s p$. germination significantly increased, its maximum values for $T$. aestivum were $64,74,64 \%$, and for $S$. cereal -75 , 74 and $65 \%$, respectively. Other types of soil and hydrogels together with algae, in comparison with the control, also had a favorable effect on this indicator. The only exception was the wheat planting on clay with hydrogels "Germany" - Ch. vulgaris and "France" - E. magnus and $S$. sp. Their germination rate was $2 \%$ lower than the control rate and amounted to 16 and $26 \%$.

Next, the combined effect of the polymer hydrogel "BSPU" and microalgae on the length of seedlings and roots of the studied seeds of higher plants was studied. For all types of soil, the smallest values of the length of $T$. 
aestivum seedlings were found in distilled water, the highest - when using the E. magnus culture liquid (Fig. 2).

The maximum value was reached when wheat was sown in sand $(18.24 \mathrm{~mm})$. Seeding of wheat on expanded clay and clay when watering with microcultures of $S$. sp. and Ch. vulgaris showed low values of the seedlings length $(13.38 \mathrm{~mm}$ and $13.77 \mathrm{~mm})$.

The use of "BSPU" hydrogel on the length of $S$. cereale seedlings in the sand also revealed a high indicator when adding E. magnus microculture (20.73 mm) (Fig. 3).

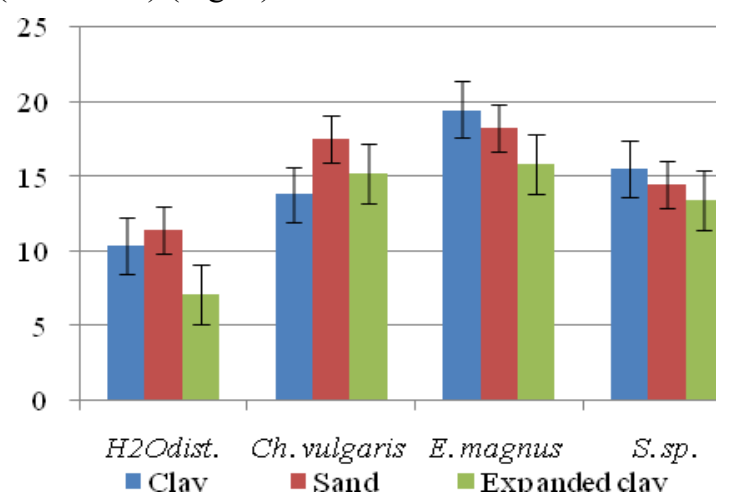

Fig. 2. Average length values of T. aestivum seedlings and the standard error of mean $(\mathrm{mm})$

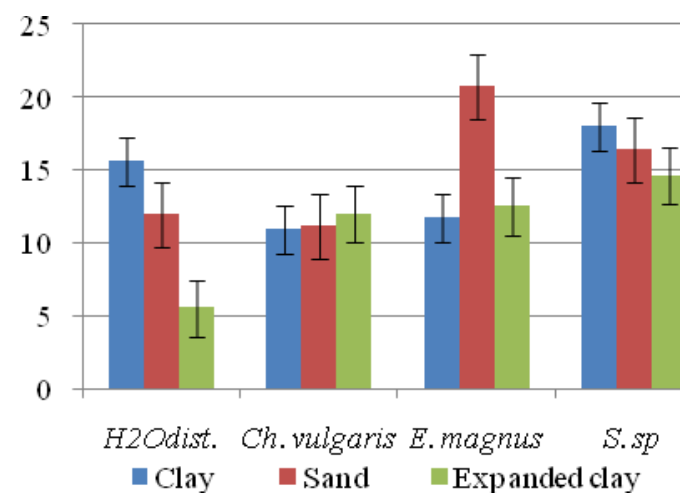

Fig. 3. Average length values of $S$. cereale seedlings and the standard error of mean $(\mathrm{mm})$

However, these indicators were not high in other two substrates (clay - $11.73 \mathrm{~mm}$, expanded clay -12.52 $\mathrm{mm})$. The lowest length values of rye seedlings were also found in experiments with Ch. vulgaris. Analysis of the average length values of the $T$. aestivum roots revealed small differences from the data on the length of seedlings. Thus, the culture liquid E. magnus demonstrated high result only when sowing on clay $(11.23 \mathrm{~mm})$. Seedings on sand and expanded clay in comparison with the other two micro-crops showed low values $(7.65 \mathrm{~mm}$ and $6 \mathrm{~mm})$.

In the sand, approximately the same results were obtained when watering $S$. sp. and Ch. vulgaris (9.28 and $8.75 \mathrm{~mm}$, respectively).

The length values of the $T$. aestivum roots were similar to their seedlings and showed the worst result when using fine-grained expanded clay (Fig. 4).

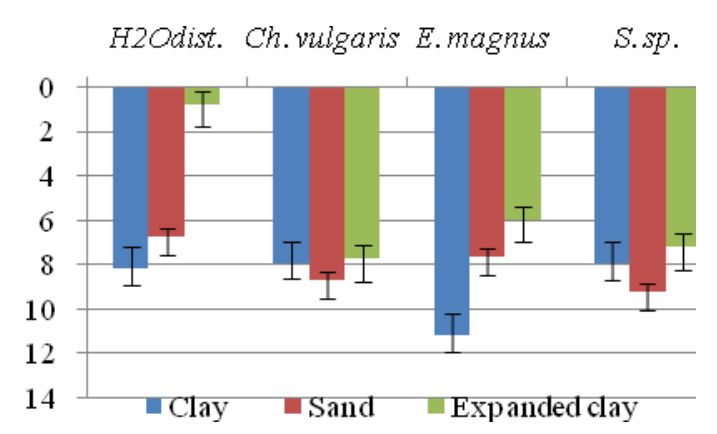

Fig. 4. Average length values of T. aestivum roots and the standard error of mean $(\mathrm{mm})$

In distilled water, the length of the roots when sown on clay was higher than in samples with culture fluids Ch. vulgaris and $S$. sp. Perhaps, some indicators decreased due to the fraction and structure of the soil and, as a consequence, the complexity of germination in such conditions. A high length indicator of the $S$. cereale roots with the use of "BSPU" hydrogel was identified when seeding in clay (Fig. 5). When adding E. magnus microculture, its value reached maximum $(20,8 \mathrm{~mm})$.

Seeding on sand showed average length values of rye roots in all the liquids used. The lowest length values of rye roots were identified in experiments with expanded clay.

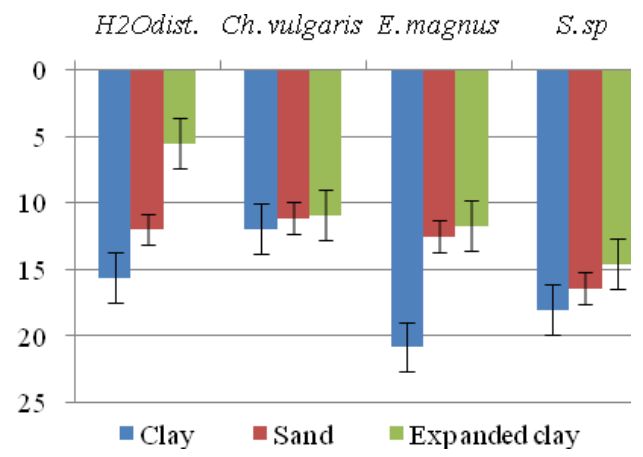

Fig. 5. Average length values of $S$. cereale roots and the standard error of mean $(\mathrm{mm})$

In general, the ratio of roots to seedlings gave similar results, which show that the use of culture fluids of microalgae E. magnus, Ch. vulgaris and $S$. sp. has a beneficial effect on the studied indicators and stimulates the growth and development of grain crops.

\section{Conclusion}

By analyzing the results obtained on the germination of Triticum aestivum and Secale cereal seeds, it is possible to identify the optimal effect of a particular algae crop in combination with a particular hydrogel and their dependence on the type of soil. Consequently, for the first cereal crop, the best indicators were identified when seeding on expanded clay using the Chlorella vulgaris culture liquid (the total germination rate was $154 \%$ ). For rye, the best overall germination rates were identified when seeding on sand with Eustigmatos magnus culture fluid $(184 \%)$. 
Seeding on expanded clay with Scotiellopsis sp. and Chlorella vulgaris algae was higher than that of wheat (total germination rate -180 and $166 \%$, respectively). The most effective hydrogel for Triticum aestivum and Secale cereale was "BSPU", it showed the highest percentage of germination when combined with microalgae Eustigmatos magnus (total germination for wheat and rye -174 and $194 \%$, respectively). The combined effect of this hydrogel with other algae also significantly increased the germination of two grain varieties.

In addition, obtained data on the length of seedlings and roots of cereals seeds allowed us to build a number of effective effects of microalgae: E. magnus $>S$. sp. > Ch. vulgaris.

Thus, the use of hydrogels and culture fluid of microalgae positively affected the germination, growth and viability of Triticum aestivum and Secale cereale seedlings on barren substrates. Subsequently, taking into account the individuality of the crop in combination, substrate/hydrogel/microalgae will provide the possibility of their joint use in the reclamation processes.

\section{References}

1. V.I. Starovoitov, O.A. Starovoitova, A.A. Manohina, Features of technology and machinery or the Jerusalem artichoke cultivation, Farm machinery operator, 11, 4-5 (2015)

2. V.K. Dridiger, V.I. Yanov, Influence of hydrogel and manure on the photosynthetic activity and productivity of wormwood estragon in dry steppe zone of Kalmykia, Bull. of the Ulyanovsk State Agricult. Acad., 2, 13-18 (2012)

3. P.V. Naumov, L.F. Scherbakova, A.A. Okolelova, Optimization of soil moisture using the polymer hydrogel, Bulletin of Nizhnevolzhsk Agricultural University Complex, 44, 77-81 (2011)

4. R. Hayat, S. Ali, Water absorption by synthetic polymer (Aquasorb) and its effect on soil properties and tomato yield, Int. J. Agri. Biol., 6, 998-1002 (2004)

5. D. Jhurry, Agricultural polymers, in: Conf. Proc. AMAS, pp. 109-113 (1997)

6. A.N. Tseplyaev et al., Analysis of existing technologies for adding copolymers and prospects for their use, in: Proc. of the Int. sci. and pract. Conf. "Scientific basis of the strategy for the development of agriculture and rural areas in the WTO,” vol. 3 (VolSAU, Volgograd, 2014)

7. R.R. Kabirov, E.S. Purina, L.M. Safiullina, Soil algae: Qualitative composition, quantitative characteristics, and use in ecological monitoring, Advan. in Modern Natural Sci., 5, 54-55 (2008)

8. M.M. Gollerbach, E.A. Shtina, Soil algae (Nauka, Leningrad, 1969)

9. A.I. Stifeev, Role of microalgae in crop production, in: Mater. of the V Int. sci. and pract. Conf. "Environmental safety of the region," pp. 219-222, (Publ. house "RIO BSU", Bryansk, 2012)

10. V.A. Lukyanov, A.I. Stifeev, Applied aspects of microalgae application in agrocenosis (Publ. house of the Kursk State Agricult. Acad., Kursk, 2014)

11. A.E. Tleukeeva, L.Sh. Shaidullina, A.U. Isaeva, V.A. Linnik, V.G. Kaplunenko, Effect of suspension of green microalgae on crop seeds germinating, Fen-Nauka, 10, 39 (2013)

12. L.S. Gil, A.I. Pashkovsky, L.T. Sulima, Modern vegetable growing of the closed and open ground, Practical guide (Publ. house Ruta, Zhytomyr, 2012)

13. F.H. Khaziev, Soil ecology in Bashkortostan (Ufa: Gilem, 2012)

14. Interstate standard GOST 32496-2013, "Fillers porous for light concrete. Technical conditions" (put into execution by order of the Federal Agency for technical regulation and Metrology dated 30 December 2013, no. 2397-art.)

15. A.V. Binas, R.D. Mash, A.I. Novikov, Biological experiment at school (Moscow: Prosveshchenie, 1990)

16. R.R. Kabirov, E.V. Spackova, Assessment of the environment quality: Teaching manual (Vagant, Ufa, 2005)

17. V.M. Andreeva, Soil and aerophilic green algae (Tetrasporales, Chlorococcales, Chlorosarcinales) (Nauka, St. Petersburg, 1998)

18. H. Ettl, G. Gartner, Sullabus der Boden-, Luft- and Flechtenalgen (Gustav Fischer Verlag, Stutgart, 1995) 